\title{
Histone Acetyltransferase Mof Affects the Progression of DSS-Induced Colitis
}

\author{
Yang Yang ${ }^{a, b}$ Jingyun Guan ${ }^{a} \quad$ Abdul Sami Shaikhc Yiran Liang ${ }^{a} \quad$ Lichao Sun $^{d}$ \\ Meng Wang ${ }^{a, b}$ Danyang Li ${ }^{a, b} \quad$ Chunhong Qiu ${ }^{a}$ Xiangzhi Li ${ }^{a, b}$
}

aThe Key Laboratory of Experimental Teratology, Ministry of Education and Department of Cell and Neurobiology, School of Basic Medicine, Jinan, bShandong Provincial Key Laboratory of Animal Cells and Developmental Biology, Shandong University School of Life Sciences, Qingdao, 'Institute of Clinical Pharmacology, Qilu Hospital of Shandong University, Jinan, dState Key Laboratory of Molecular Oncology, Cancer Hospital, Chinese Academy of Medical Sciences and Peking Union Medical College, Beijing, China

\section{Key Words}

Histone acetyltransferase Mof • DSS-induced colitis $\bullet$ IBD $\bullet$ Il17a

\begin{abstract}
Background/Aims: Histone acetylation has been demonstrated to be associated with inflammation response. Histone acetyltransferase (HAT) Mof, specifically acetylating lysine 16 of histone H4 (H4K16), has been reported to regulate T cell differentiation. In addition, it has been suggested that acetylation of H4K16 is associated with the inflammatory response. We evaluated the role and potential mechanism of Mof in the development of experimental colitis. Methods: We used Mof conditional knockout mice to study the role of Mof in dextran sulfate sodium (DSS)-induced colitis and detected the differential expression of genes due to Mof deficiency involved in the inflammatory response, particularly the Th17 signaling pathway, by western blotting, quantitative PCR and RNA sequencing (RNA-seq). Results: A significant elevation of Mof was observed in colonic tissues of mice with DSS-induced colitis. Mof deficiency alleviated the severity of DSS- induced colitis in mice. We found that Th17 signaling pathway associated genes, including $I l 17 a, \| l 22, R O R \gamma t$, ROR $\alpha$, Stat3, TGF- $\beta 1$, and $I / 6$, were downregulated in colon tissues with Mof deficiency. RNA-seq data analysis suggested that 68 genes were related to inflammatory response processing and 47 genes were downregulated in Mof defective colon tissues. Conclusion: Our study demonstrated that HAT Mof is involved in the development of colitis, and the lack of Mof ameliorates DSS-induced colitis in mice.
\end{abstract}

\section{Introduction}

Inflammatory bowel disease (IBD), which includes ulcerative colitis (UC) and Crohn's disease (CD), is a group of gastrointestinal diseases characterized by chronic relapsing inflammation that most commonly affect adolescents and young adults [1]. The main symptoms of UC and CD include abdominal pain, diarrhea, rectal bleeding and abnormal 
weight loss. IBD patients with prolonged inflammation have an increased risk of colorectal cancer, which accounts for $10-15 \%$ of all deaths from IBD [2]. Currently, there is a high prevalence of IBD in North American and European, affecting up to $0.5 \%$ of the general population [3]. However, recent systematic reviews indicate that the rate of increase in IBD incidence is considerably higher in Asia [4,5]. Thus, investigating the mechanism of IBD is important in clinical practice.

The pathogenesis of IBD is complex and multifactorial as a result of different genetic, environmental, and gut microbial factors [6,7]. The most recent genome-wide association studies of IBD have identified over 200 susceptibility loci as being associated with IBD [8-11]. Nevertheless, these loci can explain only $13.1 \%$ of variance in disease liability for CD and $8.2 \%$ for UC $[9,12]$. Many environmental factors such as smoking, dietary habits, medications, and stress, play an important role in the disease development and are identified as risk factors for IBD $[13,14]$. However, further studies are needed to understand the pathogenesis of IBD.

Epigenetics is defined as regulation of heritable gene expression through epigenetic modifications without changing the sequence of the genome [15]. Epigenetic mechanisms allow cells to adapt to environmental changes by adjusting their epigenome. Thus, epigenetics bridges the gap between genes and the environment and can explain the mechanisms by which environmental factors induce pathological expression of regulatory and pro-inflammatory cytokines and determine the phenotype and function of immune cells in IBD [16]. Currently, few studies are available on the role of epigenetic mechanisms in IBD. However, epigenetic regulators of histone modification have been shown to regulate genespecific expression of T cell differentiation in the inflammatory response [17-19]. Histone acetylation is a reversible process and is dynamically regulated by histone acetyltransferases (HATs) and histone deacetylases (HDACs) [20]. Increasing evidence has implicated histone acetylation in immunological pathways [21]. Available information on the role of histone acetylation in IBD mainly come from experimental and therapeutic trials of HDAC inhibitors. Initial data have suggested that HDAC inhibitors show predominantly protective effects in models of experimental colitis [22], but more recent reports have challenged this view [23, 24]. A recent study indicates the importance of acetylation of histone 4 in the expression of inflammatory genes in experimental colitis and suggests the potential role of HAT inhibitors in IBD treatment [25].

Mof (males absent on the first) is a HAT of the MYST family that specifically acetylates lysine 16 of histone H4 (H4K16), which correlates positively with gene transcription [26, 27]. Studies indicate that Mof plays an important role in embryogenesis, oncogenesis, cell proliferation, and DNA damage repair [28, 29]. Beyond that, T cell-specific deletion of the Mof gene results in blockade of T cell differentiation, which indicates that mice with Mof deficient T cells have compromised immune systems [30]. The acetylation of H4K16 has been reported to be associated with the inflammatory response in experimental colitis [25]. However, in the present study, changes were only observed in H4K16 acetylation, and the direct role of HAT Mof in IBD was not clarified.

In this study, we examined the impact of dextran sulfate sodium (DSS)-induced colitis in wild-type (WT) and Mof conditional knockout (cKO) mice and showed that Mof deficiency attenuated the inflammatory response in mice with DSS-induced colitis. The cytokines implicated in the Th17 signaling pathway were found to be downregulated in the colon of Mof-cKO mice. We also demonstrated changed gene expression profiles induced by Mof deficiency. Our results suggest that HAT Mof may play an enhance role in the development of experimental colitis and provide further understanding of the role of the specific HATs in IBD which may lead to new therapeutic strategies for IBD.

\section{Materials and Methods}

Mice

WT, $M o f^{\mathrm{f} / \mathrm{fl}}$ and ER-Cre mice with a C57BL/6 background were housed in a temperature-controlled environment. To generate $M o f$-cKO mice, $M o f^{\mathrm{n} / \mathrm{fl}}$ mice were crossed with $E R$-Cre mice to generate $M o f^{\mathrm{f} / \mathrm{fl}} ; E R$ - 
Yang et al.: Mof in Inflammatory Bowel Disease

$\mathrm{Cr}^{+}$mice. $M o f^{\mathrm{fl} / \mathrm{fl}} ; E R-C r e^{-}$and $M o f^{\mathrm{fl} / \mathrm{fl}} ; E R-C r e^{+}$male littermates were used for animal experiments. Genotyping was performed as previously described [31]. To deplete Mof, tamoxifen (TAM; Sigma) in sunflower oil was administered by intraperitoneal injection for 5 days at a dose of $100 \mathrm{mg} / \mathrm{kg}$ per day. Four days after the last dose, experiments were conducted. All animal experiments were conducted in accordance with the Guide for the Care and Use of Laboratory Animals published by the National Institutes of Health.

Induction of colitis

To induce colitis, 6- to 8-week-old male mice were given 3.5\% DSS (molecular weight, 5000 Da; Wako) solution to drink for either 3 or 7 days. The control group of mice were given water. During the 7 days of experimentation, body weight was assessed daily. All mice were anesthetized before sacrifice, and colon length was measured (anus to cecum).

\section{Histopathological analysis}

After the mice were sacrificed, the distal colonic tissue sections were fixed in $10 \%$ formalin solution, embedded in paraffin, cut into $5 \mu \mathrm{m}$ sections, and stained with hematoxylin and eosin (H\&E) for histopathological analysis. The histological score of individual mice was presented as previously described [32].

\section{RNA isolation and quantitative PCR}

Total RNA was extracted with TRIzol reagent (TaKaRa). RNA was reverse transcribed into cDNA with RevertAid First Strand cDNA Synthesis Kit (Thermo). Amplification was performed with SYBR Premix ExTaq Kit (TaKaRa). The mRNA level of each target gene was normalized to Gapdh. The relative gene expression was determined as $\Delta \Delta \mathrm{CT}=\Delta \mathrm{CT}$ (experiment) $-\Delta \mathrm{CT}$ (control) and expressed as fold change $\left(=2^{-\triangle \Delta C T}\right)$. Primers for Gapdh and Il22 were previously described [33]. The sequences of the primers used were: Mof-F: 5'-ACCTGGGCAAACTCAGCTAC-3', Mof-R: 5'-AGATAACATGCTGGCCCTTCC-3'; Il17a-F: 5'-GCACTTTACCTCCCCAGCTT-3', Il17a-R: 5'-TTCCCTGGCTAGAGAGCATC-3'; RoRa-F: 5'-CGAGCCCCGATGTCTTCAA-3', RoRa-R: 5'TCGTCTTCGGTCAGGTGCAT-3'; $\quad$ ROR $\gamma T$-F: 5'-CTGGGATCCACTACGGGGT-3', ROR $\quad$ 5'-RCT: Stat3-F: 5'-GATGTCCCCCCGCACTTTAG-3', Stat3-R: 5'- CCATGTCAAACGTGAGCGACT-3'; TGF 31 -F: 5'-CAGCAACAATTCCTGGCGATAC-3', TGFß1-R: 5'-TCAACCACTGCCGCACAACT-3'; Il6-F: 5'-CAATCTGGATTCAATGAGGAGAC-3', Il6-R: 5'-CTCTGGCTTGTTCCTCACTACTC-3'.

\section{Western blotting}

Total protein from colon tissues of mice was extracted with lysis buffer and separated by SDS-PAGE then transferred onto polyvinylidene fluoride membranes membranes. Antibodies against Mof (Affinity), H4K16ac, IL17A, and GADPH (Proteintech) were used for western blotting, and the secondary antibodies conjugated with HRP were used to show the bands. The immune complexes were detected with an enhanced chemiluminescence kit and analyzed with Image J software.

\section{Intestinal tissue specimens and immunohistochemistry}

Colon tissue sections were deparaffinated with xylene and rehydrated in alcohol. Antigen retrieval was achieved by heating twice in a microwave in a citric acid/citrate buffer ( $\mathrm{pH} \mathrm{6.0)}$ ). Endogenous peroxidase activity was blocked by $3 \% \mathrm{H} 202$ for $15 \mathrm{~min}$ in the dark. Sections were blocked in $5 \%$ BSA at $37{ }^{\circ} \mathrm{C}$ for $30 \mathrm{~min}$. Slices were incubated with a primary antibody overnight at $4{ }^{\circ} \mathrm{C}$, followed by washing with PBS and incubating with an HRP-labeled secondary antibody for 1 hour at $37^{\circ} \mathrm{C}$. Slides were stained with 3 , 3'-diaminobenzidine, counterstained with hematoxylin and mounted.

\section{Chromatin Immunoprecipitation}

The minced colon tissue of Mof-cKO and control mice were cross-linked using 1\% paraformaldehyde for $20 \mathrm{~min}$. The chromatin samples were sonicated for $10 \mathrm{~min}$ of $5 \mathrm{sec}$ on/10 sec off sonication cycle. Chromatin Immunoprecipitation (ChIP) was performed with SimpleChIP Plus Sonication Chromatin IP Kit (\#56383, Cell Signaling) according to the manufacturer's instructions. An anti-Mof antibody (T13H1B2, Santa Cruz) was used for ChIP. ChIP-enriched DNA was quantified by real-time PCR. The primer sequences used were: Il17a-F: 5'-TAGAACGTGTTCCGTTGGTGT-3', Il17a-R: 5'- GAGAGCATCCCTTGCCCAAA-3'; RoR $\gamma t$-F: 5'-TTCAGTCTCCCTGGGGCTAA-3', RoR $\gamma t$-R: 5'-GCTTCACACTGTGCAACCAG-3'. 


\section{Cellular Physiology Cell Physiol Biochem 2018;47:2159-2169 \begin{tabular}{l|l} 
DOI: 10.1159/000491527 & O 2018 The Author(s). Published by S. Karger AG, Basel \\
www.karger.com/cpb
\end{tabular} \\ Yang et al.: Mof in Inflammatory Bowel Disease}

Statistical analysis

All data were presented as the mean \pm SD. Statistical analysis of differences between two groups was performed using unpaired t-test with GraphPad Prism 6.0 software. $p<0.05$ was considered to be statistically significant.

\section{Results}

Expression of Mof increases in colon tissues due to DSS treatment

To determine the involvement of Mof in the inflammatory response, mRNA and proteins were extracted from colon mucosal tissues of DSS- induced colitis mice for 3 or 7 days and control mice. In addition, paraffin-embedded colonic sections from the two groups of mice were prepared for immunohistochemistry (IHC). As shown in Fig. 1A, the mRNA level of Mof was significantly increased in colonic tissues after DSS treatment on days 3 or 7 . Consistent with the change in mRNA expression, Mof protein was dramatically increased in colon tissues following DSS treatment as shown in Fig. 1B. As a specific catalytic substrate of Mof, H4K16ac showed a consistent change (Fig. 1B). Fig. 1C shows the relative intensity of Mof and H4K16ac similar to the results shown in Fig. 1B. We also identified Mof using IHC with anti-Mof antibody, and showed that more Mof protein was present in colon mucosal tissues of DSS-treated mice compared with control mice (Fig. 1D). These results demonstrated that Mof is involved in the development of colitis induced by DSS and suggested its potential role during the development of experimental colitis.

Mof deficiency reduces the severity of DSS-induced colitis in mice

To determine the role of Mof in DSSinduced colitis, we generated $M o f^{f / / f l} ; E R$ $\mathrm{Cre}^{+}$(Mof-cKO) mice with a conditional deletion of Mof after TAM treatment by crossing $M o f^{f / / f l}$ with $E R$-Cre mice. Genotypic analysis of $M o f^{f / / f l} ; E R \mathrm{Cre}^{+}$mice is shown in Fig. 2A. Approximately $80 \%$ reduction of Mof mRNA expression was found in colonic tissues of Mof-cKO mice after TAM treatment (Fig. 2B). Similarly, the protein level of Mof was significantly decreased (Fig. 2C). No differences were observed in body weight between WT and Mof-cKO mice before exposure to DSS (Fig. 2D). On day 7 after

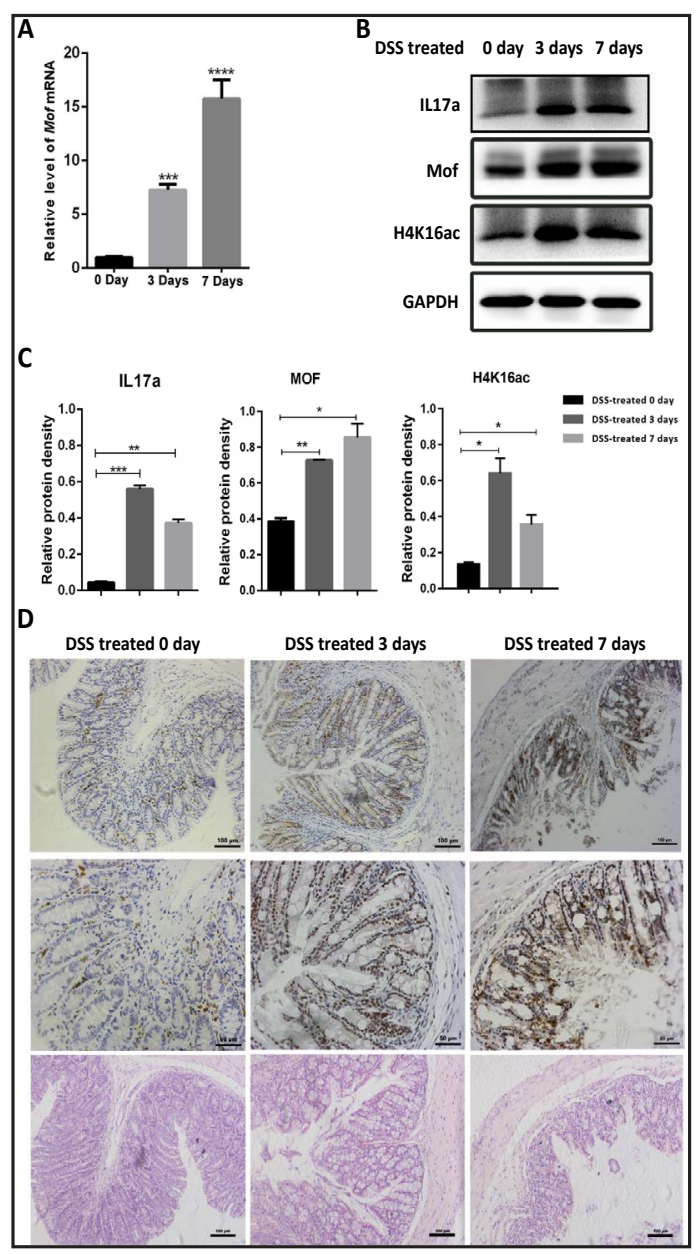

Fig. 1. Expression of Mof was increased during DSSinduced colitis in mice.(A) qPCR analysis of Mof mRNA expression in colonic tissues of mice after $3.5 \%$ DSS treatment for 3 or 7 days. (B)Expression of Mof and H4K16ac detected by western blotting during DSS-induced colitis in mice. GAPDH serves as a loading control. IL17a serves as a positive control protein which has been reported to be changed during DSS-induced colitis. (C) Relative intensity of IL17a, Mof and H4k16ac protein (GAPDH = 1). (D) Representative results show IHC staining of Mof in sections of colonic tissues from DSS-treated mice. Scale bar, $100 \mu \mathrm{m}$ (top panel) and $50 \mu \mathrm{m}$ (middle panel). Bottom panel shows the H\&E staining results that correspond to IHC. Data are presened as the mean \pm SD of three independent experiments. t-test: ${ }^{*} \mathrm{p}<0.05{ }^{* *} \mathrm{p}<0.01{ }^{* * *} \mathrm{p}<0.001$. 
exposure to DSS, compared with Mof-cKO mice, WT mice developed more severe colitis symptoms characterized by increased weight loss (Fig. 2D). The average colon length of Mof-cKO mice following DSS treatment was longer than that of WT mice exposed to DSS (Fig. 2E and F). H\&E staining of the colon sections showed, microscopically, mild inflammation in Mof-cKO mice as compared with usignificant mucosal ulceration, missing intestinal villi, colonic wall thinning and inflammatory cell infiltration in WT mice (Fig. 2G). Histological scores were used to statistically evaluate the morphological changes. The mean histological scores were significantly elevated in both WT and Mof-cKO mice with colitis but were higher in the WT mice (Fig. 2H). Taken together, these data indicate that $M o f$ deficiency ameliorates DSS-induced colitis in mice.

Series of Th17-associated genes is reduced during Mofdeficiency

It's previously shown that IL17A produced by $\mathrm{T}$ helper (Th17) cells is an important proinflammatory cytokine which has been implicated in many human autoimmune diseases including arthritis, multiple sclerosis and IBD [34-36]. To examine the potential function of Mof in colonic tissues, we therefore tested the expression of IL17A in colonic tissues obtained from Mof-cKO mice and control mice without colitis. Western blotting analysis showed that the level of IL17A protein was dramatically decreased in Mof deficient colonic tissues (Fig. 3A). The mRNA levels of $I I 17 a$ and II22, another

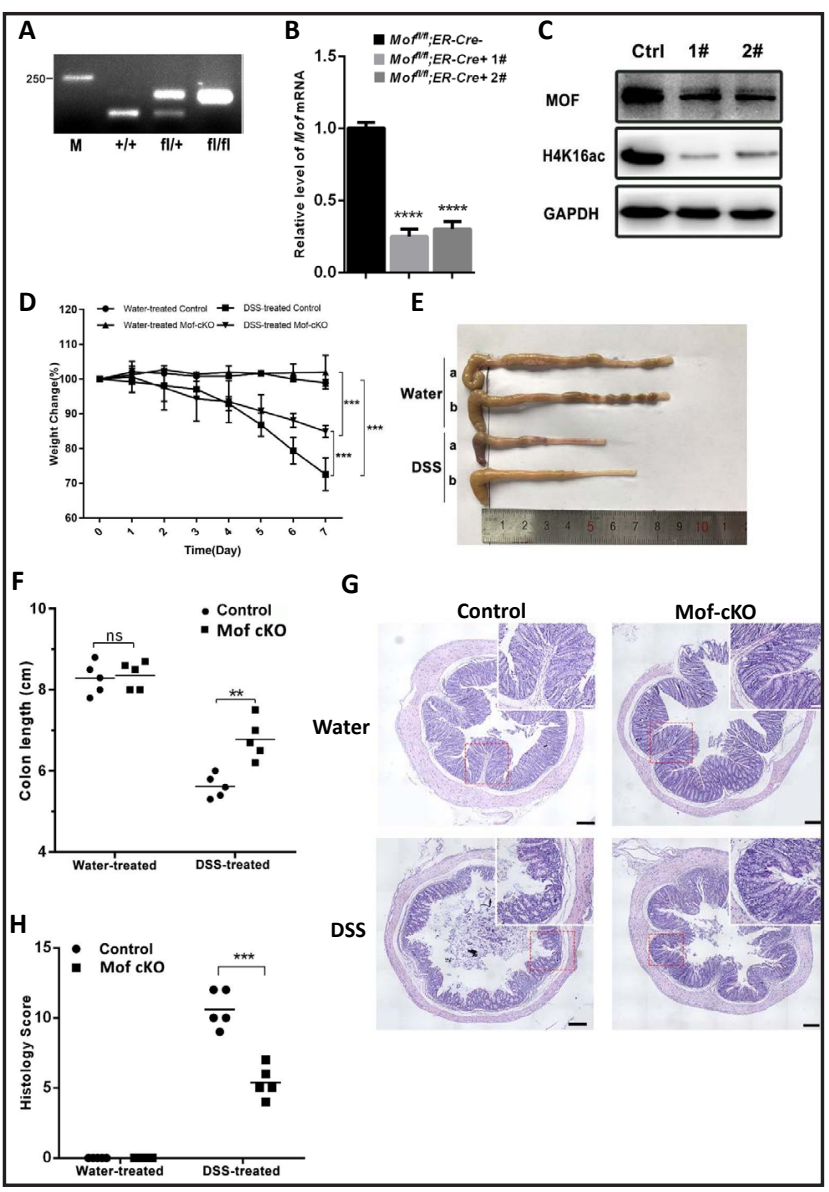

Fig. 2. Conditional deficiency of Mof ameliorates DSS-induced colitis in mice.(A) Genotyping analysis of WT, Mof ${ }^{\mathrm{fl} /+}$; ER-Cre ${ }^{+}$ and Mof ${ }^{\mathrm{f} / \mathrm{fl}}$; ER-Cre ${ }^{+}$mice. M: DNA Maker. A representative image is shown. $(\mathrm{B}, \mathrm{C})$ Expression of Mof in the colonic tissues of Mof ${ }^{\mathrm{f} / \mathrm{fl}}$; ER-Cre ${ }^{-}$mice and Mof ${ }^{\mathrm{f} / \mathrm{fl}}$; $\mathrm{ER}^{-\mathrm{Cre}^{+}}$mice at 4 days after intraperitoneal injection of TAM for 5 days detected by qPCR (B) and western blotting (C). 1\# and 2\# represent two randomly selected mice. (D-H) Conditional deficiency of Mof reduces the severity of DSS-induced colitis. (D) Changes of weight in control mice $(n=5)$ and Mof-cKO mice $(n=5)$ with DSS treatment or water. (E, F) Colon length was measured after sacrifice after 7days of treatment with DSS or water. a: control mice; b: Mof-cKO mice. (G) Representative H\&Estained colon sections of the mice described in (E). Red boxed area is enlarged in the top right corner. Scale bar, $200 \mu \mathrm{m}$ (black) and $50 \mu \mathrm{m}$ (white). (H) Histopathological analysis of the H\&E-stained sections. Data are shown as mean \pm SD of three independent experiments. ${ }^{* *} \mathrm{p}<0.01 ;{ }^{* * *} \mathrm{p}<0.001$; $* * * * \mathrm{p}<0.0001 ;$ ns, non-significant. cytokine secreted by Th17 cells, were also profoundly reduced in Mof-cKO samples (Fig. 3B). Steroid receptor-type nuclear receptors $\mathrm{ROR} \gamma \mathrm{t}$ and $\mathrm{ROR} \alpha$, the key transcription factors for Th17 cells, are important for the maintenance of IL17 expression and Th17-related genes [37]. Next, to explore the cause of II17a reduction due to Mof deficiency, we performed quantitative PCR (qPCR) analysis, and the results showed that the mRNA level of $R O R \gamma t$ and $R O R \alpha$ were both decreased following the 
deletion of Mof in colonic tissues (Fig. 3C). Furthermore, Stat3 expression, which is required for ROR $\gamma$ t activity and cytokine production [36], was also reduced in Mof-cKO colonic tissues (Fig. 3C). Given the critical role of Mof in T-cell differentiation [30], we next investigated the impact of Mof on genes related to Th17 cell differentiation. Transforming growth factor $\beta 1$ (TGF- $\beta 1$ ) and IL-6 have been reported to initiate Th17 cell differentiation. TGF- $\beta 1$ and Il6 showed low expression during Mof deficiency (Fig. 3D), suggesting a contribution of Mof to Th17 cell differentiation.

Given that Mof is a well-known transcriptional coactivator for regulating the expression of target genes, we performed ChIP studies by using the colonic tissues of $M o f^{\mathrm{fl} /+}$; $E R \mathrm{Cre}^{+}$mice, $M o f^{f / / f l} ; E R \mathrm{Cre}^{+}$mice and $M o f^{\text {fl/fli }}$;ER Cre $^{-}$control mice to assess whether Jmjd3 binds to the $R O R \gamma t$ and Il17a locus directly. We found that Mof binds at the ROR $\gamma t$ and $I I 17 a$ promoter locus in colonic tissues of control mice and Mof deletion led to reduced-Mof binding, which was positively associated with Mof expression (Fig. 3E). Our results indicated that Mof regulates many Th17-associated genes, including Il17a, Il22, RORyt, ROR $\alpha$, Stat3, $T G F-\beta 1$, and Il6. Mof may be crucially involved in the IL17A-induced inflammation in DSS-induced colitis.

Changes in gene expression profiles in colonic tissues due to Mof deficiency

To further explore other potential mechanisms through which Mof induces inflammation in DSS-induced colitis, we subsequently performed RNA sequencing (RNA-seq) with colon tissues of Mof-cKO and control mice without colitis. RNA-seq data analysis identified 655 genes that changed significantly, including 313 upregulated and 342 downregulated genes (Fig. 4A and B). Gene ontology analysis of the differentially expressed genes indicated that Mof mainly regulates cellular processes, environmental information processing, human diseases such as autoimmune disease and cancer, metabolism and organismal systems (Fig. 4C). Among the 655 differentially expressed genes, 68 (10.4\%) were related to inflammatory response processing or immune disease with 47 genes downregulated (Fig. 4D). The signaling pathway of these genes are described in Table 1. RNA-seq data analysis implied that Mof may have a role in a variety of diseases associated with inflammation through complex mechanisms.

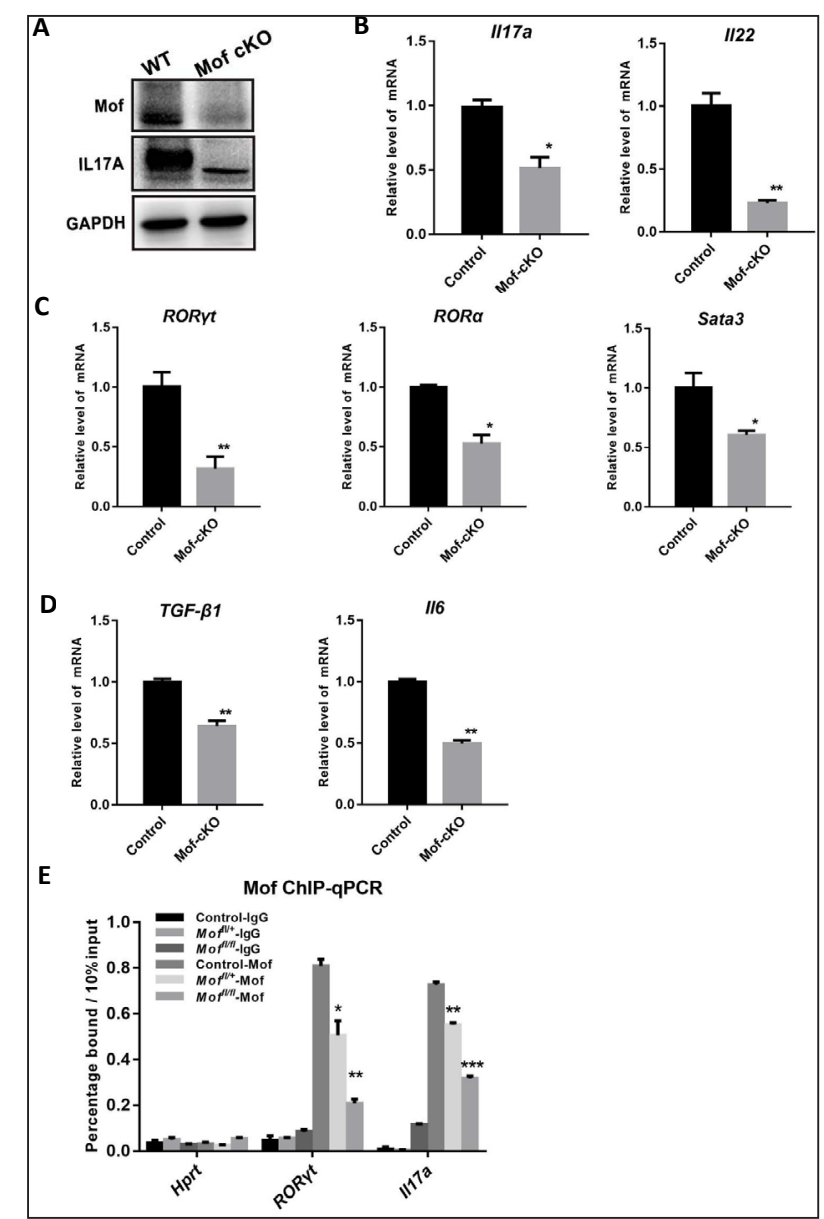

Fig. 3. Expression of Th17-associated genes decreased with Mof deficiency.(A) Expression of IL17A in colonic tissues from control and Mof-cKO mice detected by western blotting. GAPDH serves as a loading control. (B-D) qPCR analysis of the mRNA expression of Th17-associated genes in colonic tissues of control and Mof-cKO mice. (E) ChIPqPCR analysis of the binding of Mof and control IgG to the RoR $\gamma$ t and Il17a promoter in the colonic tissues of WT, mice. Data are shown as mean \pm SD of three independent experiments. ${ }^{*} \mathrm{p}<0.05 ;{ }^{* *} \mathrm{p}<0.01 ;{ }^{* * *} \mathrm{p}<0.001$. heterozygous Mof deletion and homozygous Mof deletion 


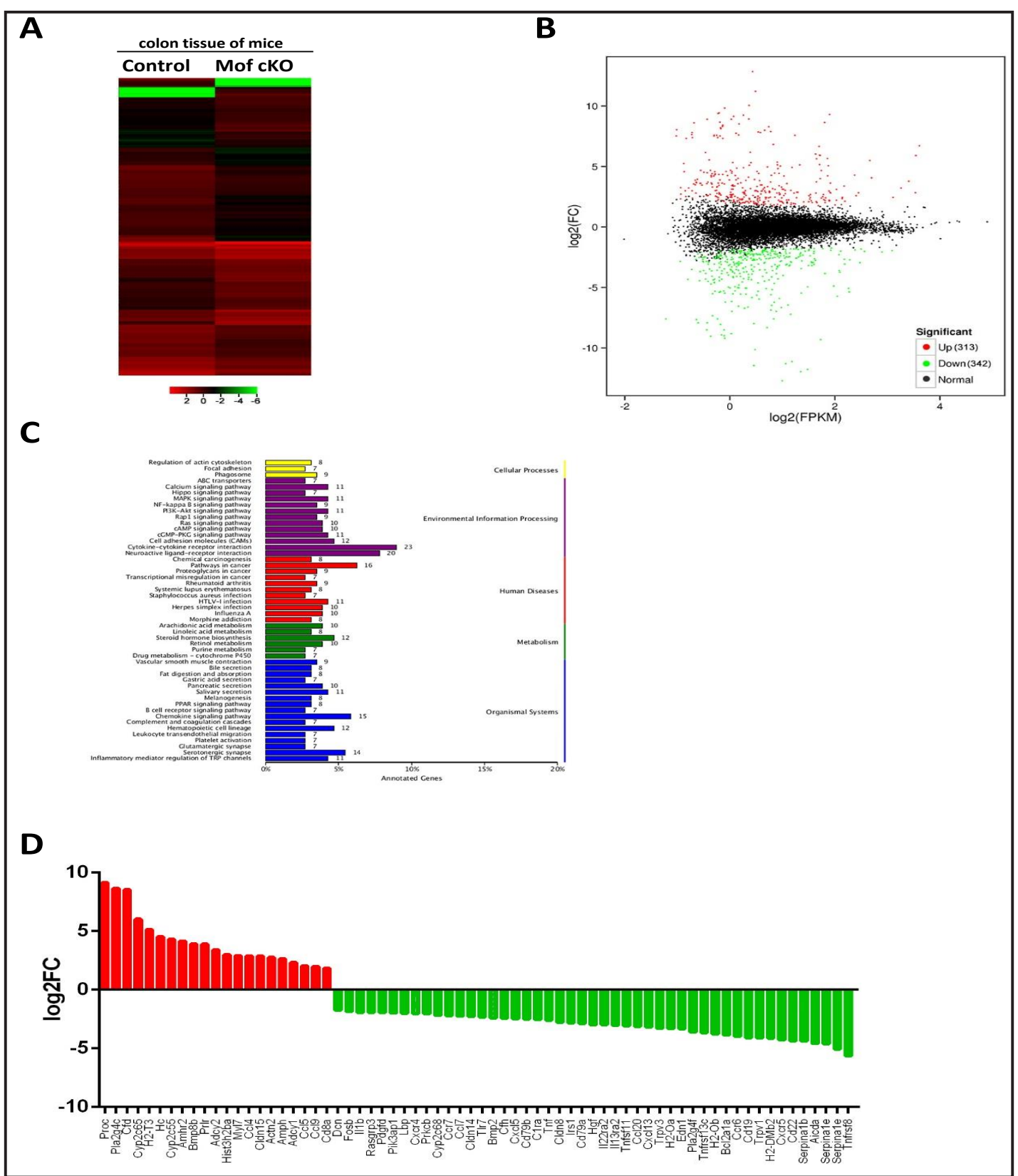

Fig. 4. Changes in the gene expression profiles in colonic tissues due to Mof deficiency by RNA-seq.(A) Global heat map analysis of expression profiles of mRNAs in colonic tissues of control and Mof-cKO mice by RNA-seq. (B) Differentially expressed genes; each point in the graph represents a gene. Green points represent downregulated genes $(n=342)$, and red points represent upregulated genes $(n=313)$. (C) KEGG classification diagram of differential gene expression. Y-axis shows the KEGG pathway name, and X-axis represents the number and the proportion of genes annotated to the pathway. (D) Expression of 68 genes involved in inflammatory response processing or immune disease in colonic tissues of Mof-cKO mice compared with control mice.

\section{Discussion}

IBD is a complex and multifactorial inflammatory disorder of the gastrointestinal tract as a resulting from the interplay between different genetic, environmental, and gut microbial factors. Given the complex etiology and lack of a curative therapy for IBD, the current 
Table 1. The genes related to inflammatory response processing changed by Mof depletion in colon tissues. Black bold: upregulated; Italic: downregulated

\begin{tabular}{|c|c|c|c|c|c|c|c|}
\hline Symbol & $\log 2 \mathrm{FC}$ & P-value & KEGG_pathway & Symbol & bog2FC & P-value & KEGG_pathway \\
\hline ADCY2 & 3.39 & $2.09 \mathrm{E}-05$ & \multirow{9}{*}{ Chemokine signaling pathway } & PLA2G4c & 8.64 & $1.73 \mathrm{E}-20$ & \multirow{10}{*}{ Inflammatory mediator regulation of TRP channels } \\
\hline CCL4 & 2.87 & $7.29 \mathrm{E}-03$ & & CYP2C65 & 6.03 & $3.03 \mathrm{E}-13$ & \\
\hline ADCY1 & 2.32 & $6.45 \mathrm{E}-03$ & & CYP2C55 & 4.29 & $9.90 \mathrm{E}-09$ & \\
\hline CXCR5 & -4.27 & $4.39 \mathrm{E}-07$ & & TRPV1 & -4.11 & $1.92 \mathrm{E}-04$ & \\
\hline CCR6 & -3.98 & $7.32 \mathrm{E}-06$ & & PLA2G4f & -3.60 & $1.23 \mathrm{E}-06$ & \\
\hline CXCL13 & -3.15 & $1.87 \mathrm{E}-05$ & & TRPV3 & -3.27 & $5.93 \mathrm{E}-06$ & \\
\hline CCR7 & -2.20 & $6.55 \mathrm{E}-03$ & & CYP2C68 & -2.18 & $1.50 \mathrm{E}-03$ & \\
\hline CCL5 & 2.02 & $3.61 \mathrm{E}-03$ & & PROC & 9.14 & $3.23 \mathrm{E}-08$ & \\
\hline CCL9 & 1.97 & $4.17 \mathrm{E}-03$ & & CFD & 8.52 & $1.03 \mathrm{E}-06$ & \\
\hline TNFRSF8 & -5.64 & $6.45 \mathrm{E}-11$ & \multirow[t]{3}{*}{ Cytokine-cytokine receptor interaction } & $\mathrm{HC}$ & 4.52 & $3.85 \mathrm{E}-04$ & \\
\hline $\mathrm{HGF}$ & -2.98 & $8.18 \mathrm{E}-05$ & & SERPINA1e & -4.61 & $3.06 \mathrm{E}-04$ & \multirow[t]{6}{*}{ Complement and coagulation cascades } \\
\hline PDGFD & -1.93 & $9.14 \mathrm{E}-03$ & & SERPINA1b & -4.38 & $7.97 \mathrm{E}-04$ & \\
\hline BCL2a1 & -3.84 & $6.08 \mathrm{E}-04$ & \multirow{6}{*}{ NF-kappa B signaling pathway } & C1RA & -2.52 & $3.36 \mathrm{E}-04$ & \\
\hline CCL19 & -5.06 & 3.89E-05 & & $\mathrm{CFH}$ & -2.43 & $5.60 \mathrm{E}-04$ & \\
\hline TNFRSF13c & -3.66 & $4.83 \mathrm{E}-06$ & & CLDN15 & 2.85 & $4.89 \mathrm{E}-05$ & \\
\hline TNFRSF11 & -3.08 & 3.83E-03 & & MYL7 & 2.89 & $4.62 \mathrm{E}-04$ & \\
\hline PRKCB & -2.02 & $3.44 \mathrm{E}-03$ & & ACTN2 & 2.76 & $2.27 \mathrm{E}-03$ & \multirow[t]{4}{*}{ Leukocyte transendothelial migration } \\
\hline LBP & -2.01 & $5.30 \mathrm{E}-03$ & & CLDN8 & -2.76 & $8.34 \mathrm{E}-05$ & \\
\hline CD22 & -4.36 & $4.56 \mathrm{E}-08$ & & CLDN14 & -2.26 & $2.69 \mathrm{E}-03$ & \\
\hline CD19 & -4.09 & $1.80 \mathrm{E}-07$ & \multirow{4}{*}{ B cell receptor signaling pathway } & CCL20 & -3.12 & $7.77 \mathrm{E}-05$ & \\
\hline CD79a & -2.87 & $5.95 \mathrm{E}-05$ & & CXCL5 & -2.46 & $2.74 \mathrm{E}-03$ & \multirow{3}{*}{ IL-17 signaling pathway } \\
\hline CD79b & -2.49 & $4.46 \mathrm{E}-04$ & & CCL7 & -2.23 & $3.58 \mathrm{E}-03$ & \\
\hline RASGRP3 & -1.93 & $8.57 \mathrm{E}-03$ & & FOSB & -1.84 & $7.58 \mathrm{E}-03$ & \\
\hline $\mathrm{H} 2-\mathrm{T} 3$ & $\mathbf{5 . 1 4}$ & $2.33 \mathrm{E}-10$ & \multirow{4}{*}{ Antigen processing and presentation } & AICDA & -4.58 & $1.98 \mathrm{E}-05$ & \multirow{3}{*}{ Inflammatory bowel disease (IBD) } \\
\hline $\mathrm{H} 2-\mathrm{DMb} 2$ & -4.13 & $2.48 \mathrm{E}-07$ & & TNF & -2.59 & $5.21 \mathrm{E}-04$ & \\
\hline $\mathrm{H} 2-\mathrm{Ob}$ & -3.78 & $7.54 \mathrm{E}-07$ & & CXCR4 & -2.02 & $5.34 \mathrm{E}-03$ & \\
\hline $\mathrm{H} 2-\mathrm{Oa}$ & -3.31 & $8.42 \mathrm{E}-05$ & & IL1b & -1.93 & $8.09 \mathrm{E}-03$ & Intestinal immune network for IgA production \\
\hline AMHR2 & 4.14 & $1.74 \mathrm{E}-03$ & \multirow{3}{*}{ TGF-beta signaling pathway } & IRS1 & -2.83 & $4.36 \mathrm{E}-04$ & \\
\hline BMP8b & 2.45 & $3.32 \mathrm{E}-06$ & & PIK3AP1 & -1.97 & $5.52 \mathrm{E}-03$ & PI3K-Akt signaling pathway \\
\hline BMP2 & -2.40 & $5.13 \mathrm{E}-04$ & & TLR7 & -2.33 & $3.89 \mathrm{E}-03$ & Toll-like receptor signaling pathway \\
\hline DCN & -1.74 & $9.74 \mathrm{E}-03$ & \multirow{4}{*}{ Jak-STAT signaling pathway } & EDN1 & -3.33 & $6.68 \mathrm{E}-06$ & TNF signaling pathway \\
\hline PRLR & 3.89 & $2.15 \mathrm{E}-06$ & & CD8a & 1.82 & $8.90 \mathrm{E}-03$ & $\mathrm{~T}$ cell receptor signaling pathway \\
\hline IL113Ra2 & -3.02 & $4.68 \mathrm{E}-04$ & & AMPB & 2.64 & $1.25 \mathrm{E}-03$ & Fc gamma R-mediated phagocytosis \\
\hline II22Ra2 & -2.98 & $1.88 \mathrm{E}-04$ & & HIST3H2BA & 2.98 & $1.35 \mathrm{E}-03$ & Systemic lupus erythematosus \\
\hline
\end{tabular}

therapeutic goals are to achieve clinical remission and improve quality of life [38]. Although environmental factors provide an enormous contribution to the development of IBD, the pathogenesis of IBD remains unclear, thereby limiting the discovery of effective therapeutic targets for IBD. Considering the prominence power of epigenetic modification in regulating gene expression induced by environmental factors, studies relevant to the role of epigenetic modification in inflammation and inflammatory disease including IBD are emerging [16, 39]. Many studies have demonstrated that histone acetylation is associated with the intestinal inflammatory response. Therefore it has been suggested that HDAC inhibitors may provide a therapeutic option in IBD [40]. However, this view has recently been challenged [24]. These data highlight the importance of investigating the activity of specific regulators for histone modification in inflammatory disease.

Although preliminary evidence has demonstrated the changes of $\mathrm{H} 4$ acetylation in animal models of IBD and biopsy samples from patients with colitis [25], further studies need to address the direct role of HATs and HDACs in IBD. In our study, we observed that both Mof and acetylation of H4k16 were significantly elevated in DSS-induced colitis in mice which suggested that Mof has an active role in the process of DSS-induced colitis. To further ensure the importance of Mof in IBD pathogenesis, we investigated DSS-induced colitis in $M o f^{f l / f l} ; E R \mathrm{Cre}^{-}$control mice and $M o f^{f / / f l} ; E R \mathrm{Cre}^{+}$(Mof-cKO) mice with a conditional deletion of Mof following TAM treatment. We found that the Mof -cKO mice presented mild colitis, whereas the control mice developed severe colitis after DSS treatment, indicating that Mof deficiency ameliorates DSS-induced colitis in mice.

IL17A produced by Th17 cells functions as a pro-inflammatory cytokine in the development of IBD. Here, our results showed that a series of Th17-associated key genes, including III7a, Il22, ROR $\gamma$ t, ROR $\alpha$, Stat3, TGF- $\beta 1$, and Il6, was significantly downregulated in Mof-deficient colonic tissues. The results of Mof ChIP-qPCR illustrated that Mof binds to the promoter of $R O R \gamma t$ and $I I 17 a$, thus directly regulating their expression. Further studies are needed to explain whether or not Mof directly regulates the expression of other genes. Studies are also needed to determine how Mof affects the function and differentiation of Th17 cells, and whether the contribution of Mof to Th17-associated genes plays a key role in ameliorating DSS-induced colitis in mice. RNA-seq analysis on colonic tissues of Mof-cKO mice and control mice without colitis showed their gene expression profiles and suggested that many inflammation-associated genes (47 genes) are downreglated in Mofdeficient tissues (Fig. 4C and D), including the NF- $\kappa B$ signaling pathway, a crucial pathway in controlling inflammatory responses and fighting infection [41]. 
Yang et al.: Mof in Inflammatory Bowel Disease

In summary, these results have demonstrated that histone H4K16 acetyltransferase Mof is involved in the progression of colitis. This finding may provide a novel view for HATs as a therapeutic target in mucosal inflammation. Considering the diversity of human IBD, further studies will be needed to address the potential mechanism by which Mof contributes to the development of inflammatory diseases.

\section{Acknowledgements}

This work was supported by the National Key Research and Development Program of China (2016YFE0129200), the National Nature Science foundation (31571321), the Open Projects of State Key Laboratory of Molecular Oncology (SKL-KF-2017-17) and the Fundamental Research Funds of Shandong University (2015JC036).

\section{Disclosure Statement}

The authors declare no conflicts of interest related to this work.

\section{References}

1 Khor B, Gardet A, Xavier RJ: Genetics and pathogenesis of inflammatory bowel disease. Nature 2011;474:307-317.

- Herszenyi L, Barabas L, Miheller P, Tulassay Z: Colorectal cancer in patients with inflammatory bowel disease: the true impact of the risk. Dig Dis 2015;33:52-57.

3 Molodecky NA, Soon IS, Rabi DM, Ghali WA, Ferris M, Chernoff G, Benchimol EI, Panaccione R, Ghosh S, Barkema HW, Kaplan GG: Increasing incidence and prevalence of the inflammatory bowel diseases with time, based on systematic review. Gastroenterology 2012;142:46-54 e42; quiz e30.

4 Kaplan GG: The global burden of IBD: from 2015 to 2025. Nat Rev Gastroenterol Hepatol 2015;12:720-727.

-5 Thia KT, Loftus EV, Jr., Sandborn WJ, Yang SK: An update on the epidemiology of inflammatory bowel disease in Asia. Am J Gastroenterol 2008;103:3167-3182.

-6 Ananthakrishnan AN: Epidemiology and risk factors for IBD. Nat Rev Gastroenterol Hepatol 2015;12:205217.

-7 Baumgart DC, Carding SR: Inflammatory bowel disease: cause and immunobiology. Lancet 2007;369:16271640.

8 Jostins L, Ripke S, Weersma RK, Duerr RH, McGovern DP, Hui KY, Lee JC, Schumm LP, Sharma Y, Anderson CA, Essers J, Mitrovic M, Ning K, Cleynen I, Theatre E, Spain SL, Raychaudhuri S, Goyette P, Wei Z, Abraham C, Achkar JP, Ahmad T, Amininejad L, Ananthakrishnan AN, Andersen V, Andrews JM, Baidoo L, Balschun T, Bampton PA, Bitton A, Boucher G, Brand S, Buning C, Cohain A, Cichon S, D’Amato M, De Jong D, Devaney KL, Dubinsky M, Edwards C, Ellinghaus D, Ferguson LR, Franchimont D, Fransen K, Gearry R, Georges M, Gieger C, Glas J, Haritunians T, Hart A, Hawkey C, Hedl M, Hu X, Karlsen TH, Kupcinskas L, Kugathasan S, Latiano A, Laukens D, Lawrance IC, Lees CW, Louis E, Mahy G, Mansfield J, Morgan AR, Mowat C, Newman W, Palmieri O, Ponsioen CY, Potocnik U, Prescott NJ, Regueiro M, Rotter JI, Russell RK, Sanderson JD, Sans M, Satsangi J, Schreiber S, Simms LA, Sventoraityte J, Targan SR, Taylor KD, Tremelling M, Verspaget HW, De Vos M, Wijmenga C, Wilson DC, Winkelmann J, Xavier RJ, Zeissig S, Zhang B, Zhang CK, Zhao H, International IBDGC, Silverberg MS, Annese V, Hakonarson H, Brant SR, Radford-Smith G, Mathew CG, Rioux JD, Schadt EE, Daly MJ, Franke A, Parkes M, Vermeire S, Barrett JC, Cho JH: Host-microbe interactions have shaped the genetic architecture of inflammatory bowel disease. Nature 2012;491:119-124.

-9 Liu JZ, van Sommeren S, Huang H, Ng SC, Alberts R, Takahashi A, Ripke S, Lee JC, Jostins L, Shah T, Abedian S, Cheon JH, Cho J, Dayani NE, Franke L, Fuyuno Y, Hart A, Juyal RC, Juyal G, Kim WH, Morris AP, Poustchi H, Newman WG, Midha V, Orchard TR, Vahedi H, Sood A, Sung JY, Malekzadeh R, Westra HJ, Yamazaki K, Yang SK, International Multiple Sclerosis Genetics C, International IBDGC, Barrett JC, Alizadeh BZ, Parkes M, Bk T, Daly MJ, Kubo M, Anderson CA, Weersma RK: Association analyses identify 38 susceptibility loci for inflammatory bowel disease and highlight shared genetic risk across populations. Nat Genet 2015;47:979986. 


\section{Cellular Physiology Cell Physiol Biochem 2018;47:2159-2169

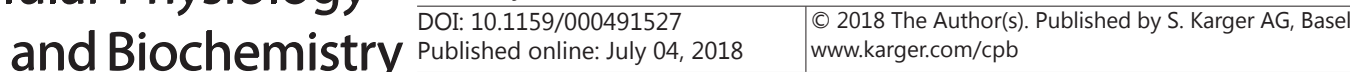

10 Qian J, Song Z, Lv Y, Huang X, Mao B: Glutathione S-Transferase T1 Null Genotype is Associated with Susceptibility to Inflammatory Bowel Disease. Cell Physiol Biochem 2017;41:2545-2552.

11 Lan X, Lan X, Chang Y, Zhang X, Liu J, Vikash V, Wang W, Huang M, Wang X, Zhou F, Chen L, Zhao Q: Identification of Two Additional Susceptibility Loci for Inflammatory Bowel Disease in a Chinese Population. Cell Physiol Biochem 2017;41:2077-2090.

12 Kmiec Z, Cyman M, Slebioda TJ: Cells of the innate and adaptive immunity and their interactions in inflammatory bowel disease. Adv Med Sci 2017;62:1-16.

13 Frolkis A, Dieleman LA, Barkema HW, Panaccione R, Ghosh S, Fedorak RN, Madsen K, Kaplan GG, Alberta IBDC: Environment and the inflammatory bowel diseases. Can J Gastroenterol 2013;27:e18-24.

$\$ 14$ Kaplan GG: Pumping Iron: Exploring Novel Gene-environment Interactions in the Inflammatory Bowel Diseases. Inflamm Bowel Dis 2017;23:1096-1097.

15 You JS, Jones PA: Cancer genetics and epigenetics: two sides of the same coin? Cancer Cell 2012;22:9-20.

16 Ventham NT, Kennedy NA, Nimmo ER, Satsangi J: Beyond gene discovery in inflammatory bowel disease: the emerging role of epigenetics. Gastroenterology 2013;145:293-308.

17 Wei G, Wei L, Zhu J, Zang C, Hu-Li J, Yao Z, Cui K, Kanno Y, Roh TY, Watford WT, Schones DE, Peng W, Sun HW, Paul WE, O'Shea JJ, Zhao K: Global mapping of H3K4me3 and H3K27me3 reveals specificity and plasticity in lineage fate determination of differentiating CD4+ T cells. Immunity 2009;30:155-167.

18 Foster SL, Medzhitov R: Gene-specific control of the TLR-induced inflammatory response. Clin Immunol 2009;130:7-15.

$>19$ Rodriguez RM, Lopez-Larrea C, Suarez-Alvarez B: Epigenetic dynamics during CD4(+) T cells lineage commitment. Int J Biochem Cell Biol 2015;67:75-85.

20 Shahbazian MD, Grunstein M: Functions of site-specific histone acetylation and deacetylation. Annu Rev Biochem 2007;76:75-100.

-21 Shakespear MR, Halili MA, Irvine KM, Fairlie DP, Sweet MJ: Histone deacetylases as regulators of inflammation and immunity. Trends Immunol 2011;32:335-343.

-22 Glauben R, Batra A, Fedke I, Zeitz M, Lehr HA, Leoni F, Mascagni P, Fantuzzi G, Dinarello CA, Siegmund B: Histone hyperacetylation is associated with amelioration of experimental colitis in mice. J Immunol 2006;176:5015-5022.

23 Li S, Fossati G, Marchetti C, Modena D, Pozzi P, Reznikov LL, Moras ML, Azam T, Abbate A, Mascagni P, Dinarello CA: Specific inhibition of histone deacetylase 8 reduces gene expression and production of proinflammatory cytokines in vitro and in vivo. J Biol Chem 2015;290:2368-2378.

24 Kroesen M, Gielen P, Brok IC, Armandari I, Hoogerbrugge PM, Adema GJ: HDAC inhibitors and immunotherapy; a double edged sword? Oncotarget 2014;5:6558-6572.

-25 Tsaprouni LG, Ito K, Powell JJ, Adcock IM, Punchard N: Differential patterns of histone acetylation in inflammatory bowel diseases. J Inflamm (Lond) 2011;8:1.

-26 Li X, Wu L, Corsa CA, Kunkel S, Dou Y: Two mammalian MOF complexes regulate transcription activation by distinct mechanisms. Mol Cell 2009;36:290-301.

-27 Taipale M, Rea S, Richter K, Vilar A, Lichter P, Imhof A, Akhtar A: hMOF histone acetyltransferase is required for histone H4 lysine 16 acetylation in mammalian cells. Mol Cell Biol 2005;25:6798-6810.

-28 Li X, Corsa CA, Pan PW, Wu L, Ferguson D, Yu X, Min J, Dou Y: MOF and H4 K16 acetylation play important roles in DNA damage repair by modulating recruitment of DNA damage repair protein Mdc1. Mol Cell Biol 2010;30:5335-5347.

29 Gupta A, Guerin-Peyrou TG, Sharma GG, Park C, Agarwal M, Ganju RK, Pandita S, Choi K, Sukumar S, Pandita RK, Ludwig T, Pandita TK: The mammalian ortholog of Drosophila MOF that acetylates histone H4 lysine 16 is essential for embryogenesis and oncogenesis. Mol Cell Biol 2008;28:397-409.

-30 Gupta A, Hunt CR, Pandita RK, Pae J, Komal K, Singh M, Shay JW, Kumar R, Ariizumi K, Horikoshi N, Hittelman WN, Guha C, Ludwig T, Pandita TK: T-cell-specific deletion of Mof blocks their differentiation and results in genomic instability in mice. Mutagenesis 2013;28:263-270.

-31 Li X, Li L, Pandey R, Byun JS, Gardner K, Qin Z, Dou Y: The histone acetyltransferase MOF is a key regulator of the embryonic stem cell core transcriptional network. Cell Stem Cell 2012;11:163-178.

-32 Kim SV, Xiang WV, Kwak C, Yang Y, Lin XW, Ota M, Sarpel U, Rifkin DB, Xu R, Littman DR: GPR15-mediated homing controls immune homeostasis in the large intestine mucosa. Science 2013;340:1456-1459. 


\section{Cellular Physiology Cell Physiol Biochem 2018;47:2159-2169 \begin{tabular}{l|l} 
DOI: 10.1159/000491527 & $\begin{array}{l}\text { O } 2018 \text { The Author(s). Published by S. Karger AG, Basel } \\
\text { www.karger.com/cpb }\end{array}$ \\
\hline
\end{tabular}}

Yang et al.: Mof in Inflammatory Bowel Disease

33 Liu Z, Cao W, Xu L, Chen X, Zhan Y, Yang Q, Liu S, Chen P, Jiang Y, Sun X, Tao Y, Hu Y, Li C, Wang Q, Wang Y, Chen CD, Shi Y, Zhang X: The histone H3 lysine-27 demethylase Jmjd3 plays a critical role in specific regulation of Th17 cell differentiation. J Mol Cell Biol 2015;7:505-516.

-34 Dardalhon V, Korn T, Kuchroo VK, Anderson AC: Role of Th1 and Th17 cells in organ-specific autoimmunity. J Autoimmun 2008;31:252-256.

-35 Korn T, Oukka M, Kuchroo V, Bettelli E: Th17 cells: effector T cells with inflammatory properties. Semin Immunol 2007;19:362-371.

-36 Ito R, Kita M, Shin-Ya M, Kishida T, Urano A, Takada R, Sakagami J, Imanishi J, Iwakura Y, Okanoue T, Yoshikawa T, Kataoka K, Mazda 0: Involvement of IL-17A in the pathogenesis of DSS-induced colitis in mice. Biochem Biophys Res Commun 2008;377:12-16.

37 Huh JR, Leung MW, Huang P, Ryan DA, Krout MR, Malapaka RR, Chow J, Manel N, Ciofani M, Kim SV, Cuesta A, Santori FR, Lafaille JJ, Xu HE, Gin DY, Rastinejad F, Littman DR: Digoxin and its derivatives suppress TH17 cell differentiation by antagonizing RORgammat activity. Nature 2011;472:486-490.

-38 Abraham BP, Ahmed T, Ali T: Inflammatory Bowel Disease: Pathophysiology and Current Therapeutic Approaches. Handb Exp Pharmacol 2017;239:115-146.

39 Zhang B, Tian Y, Jiang P, Jiang Y, Li C, Liu T, Zhou R, Yang N, Zhou X, Liu Z: MicroRNA-122a Regulates Zonulin by Targeting EGFR in Intestinal Epithelial Dysfunction. Cell Physiol Biochem 2017;42:848-858.

40 Glauben R, Siegmund B: Inhibition of histone deacetylases in inflammatory bowel diseases. Mol Med 2011;17:426-433.

41 Park JS, Lee EJ, Lee JC, Kim WK, Kim HS: Anti-inflammatory effects of short chain fatty acids in IFN-gammastimulated RAW 264.7 murine macrophage cells: involvement of NF-kappaB and ERK signaling pathways. Int Immunopharmacol 2007;7:70-77. 